\title{
The Effect of Granulocyte-colony Stimulating Factor on Rotator Cuff Healing After Injury and Repair
}

\author{
David Ross MD, Tristan Maerz MS, Michael Kurdziel MS, \\ Joel Hein MD, Shashin Doshi MD, Asheesh Bedi MD, \\ Kyle Anderson MD, Kevin Baker PhD
}

Published online: 3 March 2015

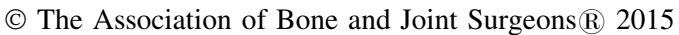

\begin{abstract}
Background The failure rate of tendon-bone healing after repair of rotator cuff tears remains high. A variety of biologic- and cell-based therapies aimed at improving rotator cuff healing have been investigated, and stem cell-based techniques have become increasingly more common. However, most studies have focused on the implantation of exogenous cells, which introduces higher risk and cost. We aimed to improve rotator cuff healing by inducing endogenous stem cell mobilization with systemic
\end{abstract}

One or more of the authors certifies that he or she, or a member of his or her immediate family, has or may receive payments or benefits, during the study period, an amount of less than USD 10,000 from Smith \& Nephew (Andover, MA, USA) and A3 Surgical (La Tronche, France) (AB); and an amount of USD 10,000 to USD 100,000 from Arthrex, Inc (Naples, FL, USA) and less than USD 10,000 from Biomet (Warsaw, IN, USA) (KA).

All ICMJE Conflict of Interest Forms for authors and Clinical Orthopaedics and Related Research ${ }^{\circledR}$ editors and board members are on file with the publication and can be viewed on request. Clinical Orthopaedics and Related Research ${ }^{\mathbb{R}}$ neither advocates nor endorses the use of any treatment, drug, or device. Readers are encouraged to always seek additional information, including FDAapproval status, of any drug or device prior to clinical use.

Each author certifies that his or her institution approved the animal protocol for this investigation and that all investigations were conducted in conformity with ethical principles of research.

This work was performed at Beaumont Health System's Orthopaedic Research Laboratories, Royal Oak, MI, USA.

D. Ross, J. Hein, K. Anderson

Department of Orthopaedic Surgery, Beaumont Health System,

Royal Oak, MI, USA

T. Maerz, M. Kurdziel, K. Baker ( $\square)$

Orthopaedic Research Laboratories, Beaumont Health System,

3811 W 13 Mile Road, Royal Oak, MI 48073, USA

e-mail: kevin.baker@beaumont.edu administration of granulocyte-colony stimulating factor (G-CSF).

Questions/purposes We asked: (1) Does G-CSF administration increase local cellularity after acute rotator cuff repair? (2) Is there histologic evidence that G-CSF improved organization at the healing enthesis? (3) Does GCSF administration improve biomechanical properties of the healing supraspinatus tendon-bone complex? (4) Are there micro-MRI-based observations indicating G-CSFaugmented tendon-bone healing?

Methods After creation of full-thickness supraspinatus tendon defects with immediate repair, 52 rats were randomized to control or G-CSF-treated groups. G-CSF was administered for 5 days after repair and rats were euthanized at 12 or 19 postoperative days. Shoulders were subjected to micro-MR imaging, stress relaxation, and load-to-failure as well as blinded histologic and histomorphometric analyses.

Results G-CSF-treated animals had significantly higher cellularity composite scores at 12 and 19 days compared with both control (12 days: $7.40 \pm 1.14$ [confidence interval $\{\mathrm{CI}\}, 5.98-8.81]$ versus $4.50 \pm 0.57$ [CI, 3.58-5.41], $\mathrm{p}=0.038 ; 19$ days: $8.00 \pm 1.00[\mathrm{CI}, 6.75-9.24]$ versus $5.40 \pm 0.89$ [CI, 4.28-6.51], $\mathrm{p}=0.023$ ) and normal animals ( 12 days: $p=0.029 ; 19$ days: $p=0.019$ ). There was no significant difference between G-CSF-treated animals or control animals in ultimate stress (MPa) and strain,

\section{S. Doshi}

Department of Diagnostic Radiology, Beaumont Health System, Royal Oak, MI, USA

A. Bedi

Department of Orthopaedic Surgery, University of Michigan

Medical School, Ann Arbor, MI, USA 
modulus (MPa), or yield stress $(\mathrm{MPa})$ and strain at either 12 days $(\mathrm{p}=1.000, \mathrm{p}=0.104, \mathrm{p}=1.000, \mathrm{p}=0.909$, and $\mathrm{p}=$ 0.483 , respectively) or 19 days $(\mathrm{p}=0.999, \mathrm{p}=0.964, \mathrm{p}=$ $1.000, \mathrm{p}=0.988$, and $\mathrm{p}=0.904$, respectively). There was no difference in MRI score between G-CSF and control animals at either 12 days $(2.7 \pm 1.8$ [CI, 1.08-4.24] versus $2.3 \pm 1.8$ [CI, 0.49-4.17], $\mathrm{p}=0.623)$ or 19 days $(2.5 \pm 1.4$ [CI, 1.05-3.94] versus $2.3 \pm 1.5$ [CI, 0.75-3.91], $\mathrm{p}=$ 0.737). G-CSF-treated animals exhibited significantly lower relative bone volume compared with normal animals in the entire humeral head (24.89 \pm 3.80 [CI, 20.17-29.60) versus $32.50 \pm 2.38$ [CI, 29.99-35.01], $\mathrm{p}=0.009)$ and at the supraspinatus insertion $(25.67 \pm 5.33$ [CI, 19.04-32.29] versus $33.36 \pm 1.69$ [CI, 31.58-35.14], $\mathrm{p}=0.027)$ at 12 days. Further analysis did not reveal any additional significant relationships with respect to regional bone volume or trabecular thickness between groups and time points ( $\mathrm{p}>0.05)$.

Clinical Relevance Postoperative stem cell mobilization agents may be an effective way to enhance rotator cuff repair. Future studies regarding the kinetics of mobilization, the homing capacity of mobilized cells to injured tissues, and the ability of homing cells to participate in regenerative pathways are necessary.

\section{Introduction}

Rotator cuff repair is a clinically successful surgical technique [6, 14, 31]; however, the widely reported clinical success does not always correlate with structural healing of the repair [12, 31, 47]; and, when evaluated critically, the failure rate of tendon-to-bone healing remains unacceptably high for large and massive tears [10, 42]. Previous studies have evaluated patient outcomes and shown that patients with a healed rotator cuff demonstrated improved strength and ROM $[6,31]$ and that retears affect the recovery of functional outcomes [16, 18, 27].

In an effort to improve tendon-to-bone healing after rotator cuff repair, numerous biologic- and tissue engineering-based techniques have been used, including use of anabolic growth factors [23, 25], proteinase inhibitors [3, 4] as well as augmentation with stem and progenitor cell populations [19, 21, 33]. Mesenchymal stem cells (MSCs) are natively involved in tissue maturation, healing, and remodeling [43] and, as a result of their migratory, multipotent, and immunomodulatory properties, possess the potential for regenerating a wide range of pathologic or degenerative tissues. The ability to differentiate into numerous cell types and potent immunomodulatory properties make the use of MSCs in rotator cuff healing an attractive treatment option [30]. However, the isolation, purification, and reimplantation of autologous MSCs are both cost- and time-intensive. Furthermore, successful engraftment of allogenic MSCs is adversely affected by MHC-mediated alloreactivity [26].

As an alternative to the isolation and reimplantation of autologous MSCs, autogenous bone marrow mobilization may be an effective way of increasing circulating stem cell populations in peripheral blood to consequently increase the number of cells that migrate to the site of injury. After severe injuries such as myocardial infarction, stroke, or blast injury, MSCs and hematopoietic stem cells (HSCs) travel from bone marrow cavities into circulating blood in a process termed "mobilization." Once in circulation, chemokine-mediated signaling causes MSCs and HSCs to "migrate" to capillary beds near the site of injury, adhere to the inner epithelial layers, and then "transmigrate" into the injured tissue to participate in regenerative processes [49]. Numerous cytokines and small molecule receptor antagonists have been shown to induce bone marrow mobilization to increase circulating stem cell concentration [28], one of which is granulocyte-colony stimulating factor (G-CSF), a glycoprotein known to participate in the native immune response [48]. G-CSF is used clinically to combat neutropenia in patients undergoing myeloablative procedures [45] and for HSC mobilization in bone marrow donation [1, 46]. G-CSF has also been shown to induce MSC mobilization from the bone marrow into the peripheral vascular system [11]. Increasing the concentration of circulating MSCs to increase the number of MSCs that migrate to a site of injury can potentially aid in tendon-tobone healing as a result of the local expression of chemokines after injury.

With this in mind, we posed the following questions: (1) Does G-CSF administration increase local cellularity after acute rotator cuff repair? (2) Is there histologic evidence that G-CSF improved organization at the healing enthesis? (3) Does G-CSF administration improve biomechanical properties of the healing supraspinatus tendon-bone complex? (4) Are there micro-MRI-based observations indicating G-CSF-augmented tendon-bone healing?

\section{Materials and Methods}

\section{Surgical Methods and Animal Groups}

Under an Institutional Animal Care and Use Committeeapproved protocol, 52 mature, female Sprague-Dawley rats received a surgically created, full-thickness supraspinatus tendon defect followed by surgical repair, as previously described [3, 4, 13, 19-21]. The left shoulder was approached through a deltoid-splitting technique. The acromioclavicular joint was separated and the anterior 
corner of the acromion was reflected to gain access to the supraspinatus tendon. A 4-0 Ethibond (Ethicon, Somerville, NJ, USA) suture was then placed in the tendon in a modified Mason-Allen configuration. The supraspinatus was sharply incised from the greater tuberosity behind the biceps tendon to the upper part of the infraspinatus; the tuberosity was then prepared by sharply scraping any remaining tendon on the tuberosity with the scalpel. Two crossed $0.35-\mathrm{mm}$ drill holes were created in the tuberosity and the free ends of the suture were passed through these to reduce the supraspinatus to the greater tuberosity footprint. The suture ends were then tied over the metaphyseal bone bridge laterally to complete the repair. The deltoid was closed with absorbable suture and the skin closed in a layered fashion. All animals were allowed ad libitum cage activity and diet for the entire postoperative period until euthanasia.

After repair, rats were randomized to either the control $(\mathrm{n}=$ 26) or G-CSF-treated $(n=26)$ group (Fig. 1). Animals in the G-CSF group received subcutaneous injections of $100 \mu \mathrm{g} / \mathrm{kg}$ G-CSF (Filgastrim; Amgen, Thousand Oaks, CA, USA) each day for 5 postoperative days. This dose mirrors clinical use of G-CSF and is commonly used within murine models to promote the mobilization of stem cells into peripheral blood [22]. The control animals received normal saline injections of equivalent volume. Rats were euthanized by $\mathrm{CO}_{2}$ asphyxiation at 12 and 19 postoperative days. These time points were selected to assess early differences between treatment groups and represent similar time points for other studies that have used G-CSF in murine models of lung contusion [22] and myocardial infarction [35]. Recent studies also indicate early systemic effects associated with G-CSF therapy [37, 41]. Shoulder specimens dedicated to biomechanical testing $(\mathrm{n}=8$ per group per time point) were dissected en bloc, wrapped in saline-soaked towels, and immediately frozen at $-20^{\circ} \mathrm{C}$ until the day of testing. Six of the shoulders dedicated to biomechanical testing were also randomized to undergo pretest micro-MR imaging before dissection preparation. Specimens dedicated to histologic analysis $(n=5$ per group per time point) were dissected to expose the humerus with the attached supraspinatus tendon and muscle and immersed fully in $10 \%$ neutral-buffered formalin (NBF) for 3 days, washed three times with phosphate-buffered saline (PBS), and stored in sterile PBS until histologic processing. Normal healthy, noninjured and nonrepaired specimens were used to define baseline levels in each analysis.

\section{Micro-MRI and Evaluation}

A 3-T (10-cm bore size) micro-MRI (MR Solutions, Guildford, UK) was used for the imaging of the supraspinatus tendon-bone complex. Fat-saturated T2-weighted fast-spin echo (FSE), sagittal T1-weighted FSE, and coronal proton density-weighted FSE sequences were used (Fig. 1; Table 1). A blinded musculoskeletal-trained radiologist (SD) evaluated and graded images of each specimen according to three qualitative categories: signal intensity, tendon thickness, and tendon retraction (Table 2). These categories were chosen based on literature describing clinical MRI evaluation of the rotator cuff using similar sequences as those used in our study $[34,38]$. An overall MRI score was calculated for each animal by summing the grade of the individual sections, and average MRI score was compared between groups.

\section{Biomechanical Testing}

Biomechanical testing was performed by two biomedical engineers (TM, MK) on a materials testing machine (MTS Insight 150; MTS Systems Corp, Eden Prairie, MN, USA).

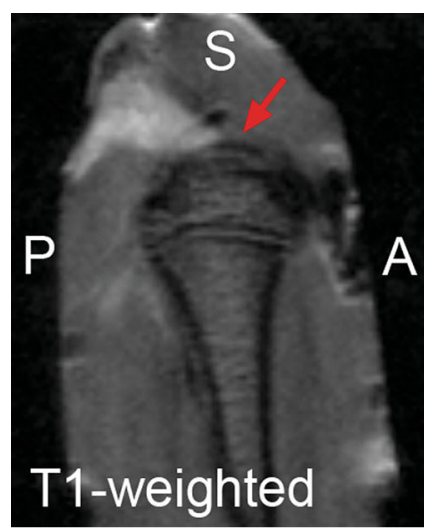

A

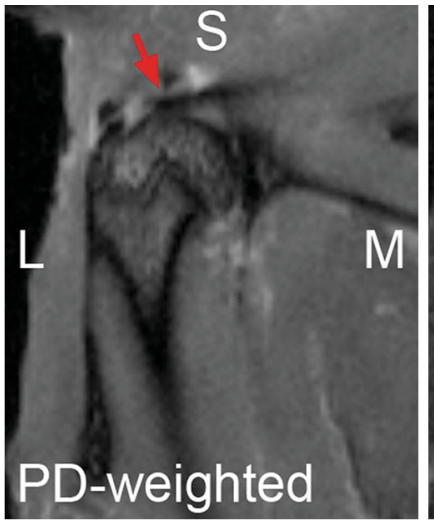

B

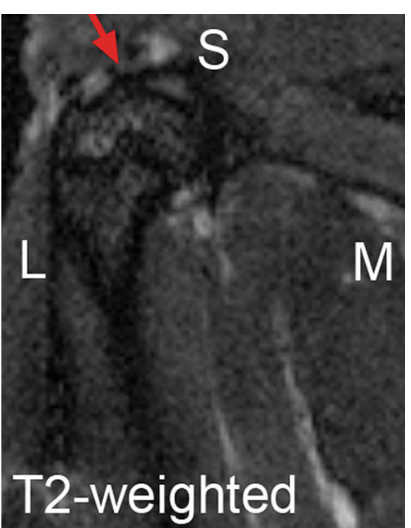

C
Fig. 1 A-C (A) Sagittal, T1-weighted (left) MR images of the rat shoulder show the supraspinatus tendon inserting into the humerus near the midline. (B) Coronal proton density (PD)-weighted (middle), and (C) T2-weighted (right) images show the supraspinatus tendon as a continuous dark band (red arrow). $\mathrm{A}=$ anterior; $\mathrm{P}=$ posterior; $\mathrm{S}=$ superior; $\mathrm{M}=$ medial; $\mathrm{L}=$ lateral. Red arrow designates intact $\mathrm{RC}$. 
Table 1. Micro-MRI parameters

\begin{tabular}{llcllcc}
\hline MRI sequence & Echo time $(\mathrm{ms})$ & Repetition time $(\mathrm{ms})$ & Slice thickness/gap & In-plane resolution $(\mu \mathrm{m})$ & Field of view $(\mathrm{mm})$ & Averages \\
\hline T1 FSE & 20 & 520 & $1.00 / 0.00$ & $156 \times 156$ & $40 \times 40$ \\
T2 FSE & 85 & 4800 & $0.85 / 0.00$ & $156 \times 156$ & $40 \times 40$ \\
PD FSE & 40 & 3500 & $0.85 / 0.00$ & $156 \times 156$ & $40 \times 40$ & 8 \\
\hline
\end{tabular}

$\mathrm{FSE}=$ fast-spin echo; $\mathrm{PD}=$ proton density.

Table 2. Qualitative MRI grading scheme

\begin{tabular}{ll}
\hline Category and grade & Description \\
\hline $\begin{array}{c}\text { Signal intensity } \\
0\end{array}$ & $\begin{array}{c}\text { Homogenous dark signal } \\
\text { Intermediate, inhomogeneous signal } \\
\text { with focal brightness }\end{array}$ \\
1 & Bright signal with fluid \\
2 & Normal thickness \\
Tendon thickness & $100 \%-150 \%$ of normal thickness \\
0 & $150 \%-200 \%$ of normal thickness \\
1 & \\
2 & No retraction \\
Tendon retraction & Retracted to halfway point between footprint \\
0 & and glenoid \\
1 & Retracted to glenoid or more \\
\hline
\end{tabular}

Frozen specimens were thawed to room temperature, dissected to isolate the humerus and attached to the supraspinatus myotendinous unit, and embedded in a polyester resin. Before testing, the cross-sectional area of each tendon was calculated using a custom-manufactured laser-based system previously used in biomechanical testing of rodent supraspinatus tendons [44]. Testing was performed in an environmental testing chamber containing temperature-controlled buffered saline $\left(39^{\circ} \mathrm{C}, \mathrm{pH}=7.4\right)$ with the force application along the axis of the supraspinatus tendon positioned in $15^{\circ}$ of abduction relative to the humerus. Stress relaxation testing was performed using the protocol: $0.1-\mathrm{N}$ preload, preconditioning for 10 cycles from $0.1 \mathrm{~N}$ to $0.3 \mathrm{~N}$, hold at $0.1 \mathrm{~N}$ for 300 seconds, and elongation to $5 \%$ strain at a rate of $50 \%$ / second followed by a 1200 -second relaxation period. After stress relaxation, the tendon was fully unloaded for 5 minutes and then subjected to ultimate failure testing. The tendon was preloaded, preconditioned, and loaded to failure at a rate of $0.3 \% / \mathrm{second}$ [36]. Data were collected with MTS software and analyzed using a custom program in Matlab (R2013a; Mathworks, Natick, MA, USA) to calculate the parameters from stress relaxation and load-to- failure testing: peak stress (MPa), equilibrium stress (MPa), percent relaxation, ultimate stress (MPa), ultimate strain, modulus (MPa), yield stress (MPa), and yield strain.

Histology

After fixation in $10 \%$ NBF, samples were embedded in paraffin, decalcified, and cut into coronal sections (approximately $5 \mu \mathrm{m}$ thick). Sections were spaced sequentially at the coronal center of the humerus to include the entire osseotendinous junction of the supraspinatus tendon, the supraspinatus muscle belly, and the proximal humerus. Sections were stained with Safranin-O/Fast Green (Saf-O) and hematoxylin and eosin (H\&E) and imaged at x 10 using light microscopy. Histomorphometric quantification of relative bone volume (BV/TV) and mean trabecular thickness were performed on six sections of each using the BoneJ plugin for the image-processing program ImageJ (Bone J, NIH, Bethesda, MD, USA) [8].

Qualitative analysis of the supraspinatus tendon, tendonbone insertion, and relative cellularity was performed by a blinded graduate-trained biomedical researcher (KB). Digital reconstructions of H\&E- and Saf-O-stained wholemount slides were viewed by the graders using digital pathology software (ImageScope; Leica Biosystems, Buffalo Grove, IL, USA), which permitted viewing at a range of magnifications from $\times 1$ to $\times 20$. A modified Bonar score [32], inversely proportional to tendon quality, was implemented to assess tendon integrity on digitized wholemount views of H\&E-stained sections. As part of the modified Bonar score, the blinded reviewer assessed the degree of vascularity within the tendon (score: $0-3$; infrequent vessels versus increased number of vessels), the morphology of fibroblasts within the tendon (score: 0-3; cell axis aligned with tendon versus rounded cells) as well as the degree of collagen orientation (score: 0-3; significantly maintained orientation and crimp pattern versus disorganized fibers). Metachromasia at the supraspinatus tendon-bone interface was qualitatively assessed on Saf-Ostained sections by the blinded reviewers. Finally, the degree of cellularity within the supraspinatus tendon, humeral bone tunnels, and within the humeral head was also 
Table 3. Semiquantitative histology results

\begin{tabular}{lllr}
\hline $\begin{array}{l}\text { Treatment } \\
\text { group }\end{array}$ & $\begin{array}{l}\text { Modified Bonar score } \\
(\text { mean } \pm \text { SD } \\
[95 \% \mathrm{CI}])\end{array}$ & $\begin{array}{l}\text { Enthesis metachromasia } \\
\text { score }(\mathrm{mean} \pm \mathrm{SD} \\
[95 \% \mathrm{CI}])\end{array}$ & $\begin{array}{l}\text { Cellularity score } \\
(\mathrm{mean} \pm \mathrm{SD} \\
[95 \% \mathrm{CI}])\end{array}$ \\
\hline $\begin{array}{l}\text { Normal } \\
\text { Control }\end{array}$ & $2.44 \pm 0.88(1.76-3.12)$ & $2.33 \pm 0.70(1.78-2.87)$ & $3.88 \pm 1.69(2.58-5.18)$ \\
12 days & & $1.75 \pm 0.50(0.95-2.54)$ & $4.50 \pm 0.57(3.58-5.41)^{\dagger}$ \\
19 days & $5.25 \pm 0.50(4.45-6.04)^{*}$ & $2.00 \pm 0.71(1.12-2.87)$ & $5.40 \pm 0.89(4.28-6.51)^{\dagger}$ \\
G-CSF & $4.80 \pm 1.48(2.95-6.64)^{*}$ & & $7.40 \pm 1.14(5.98-8.81)^{*}$ \\
12 days & & $2.20 \pm 0.84(1.16-3.23)$ & $8.00 \pm 1.00(6.75-9.24)^{*}$ \\
19 days & $4.40 \pm 1.51(2.51-6.28)$ & $2.60 \pm 0.54(1.91-3.28)$ & \\
\hline
\end{tabular}

*Significant difference from normal; ${ }^{\dagger}$ significant difference from G-CSF; G-CSF = granulocyte-colony stimulating factor.

assessed on digitized whole-mount views of H\&E-stained sections.

Data Analysis and Statistical Methods

All statistical analysis was performed in SPSS (Version 22; IBM Corp, Armonk, NY, USA). Equal variance and normality assumptions were verified using Levene test and Shapiro-Wilk test, respectively. Differences in normally distributed and nonnormally distributed variables among normal, control, and G-CSF groups were compared using one-way analysis of variance or Kruskal-Wallis test, respectively. Post hoc comparisons were performed using a modified Bonferroni post hoc test $(\alpha=95 \%)$. Differences between two normally distributed and nonnormally distributed independent variables within each group were compared using t-tests or Mann-Whitney U tests, respectively. Ordinal data such as MRI score or histologic score were compared between groups using the Kruskal-Wallis test with a modified Bonferroni post hoc test of multiple comparisons $(\alpha=95 \%)$. Differences in ordinal data between two independent variables within each group were compared using Mann-Whitney U tests.

\section{Results}

\section{Histology}

G-CSF-treated animals had significantly higher composite scores for cellularity at both 12 and 19 days compared with both control (12 days: $\mathrm{p}=0.038 ; 19$ days: $\mathrm{p}=0.023)$ and normal animals (12 days: $p=0.029 ; 19$ days: $p=0.019)$ at both time points (Table 3). G-CSF treatment also exhibited increased cellularity in both the humeral head (12 days: $\mathrm{p}=$ 0.038; 19 days: $\mathrm{p}=0.045)$ and within the bone tunnels (12 days: $p=0.076 ; 19$ days: $p=0.044$ ) compared with control animals. Semiquantitative histologic assessment demonstrated lower modified Bonar scores for supraspinatus tendons from G-CSF animals compared with control animals at both 12 and 19 postoperative days (Table 3); however, a significant difference was not detected (12 days: $\mathrm{p}=0.719$; 19 days: $p=0.932$ ). Control animals demonstrated significantly higher modified Bonar scores compared with normal animal tendons at both time points (12 days: $\mathrm{p}=$ $0.013 ; 19$ days: $\mathrm{p}=0.022$ ).

G-CSF-treated animals exhibited significantly lower $\mathrm{BV} / \mathrm{TV}$ in the entire humeral head $(\mathrm{p}=0.009)$ and at the supraspinatus insertion $(\mathrm{p}=0.027$ ) compared with normal animals at 12 days (Table 4). There was no difference in relative bone volume of the whole humeral head (12 days: $\mathrm{p}=0.679 ; 19$ days: $\mathrm{p}=0.969)$ or supraspinatus insertion (12 days: $p=0.898 ; 19$ days: $p=0.800$ ) between control and G-CSF animals at either time point. In addition, there was no difference in relative bone volume of the whole humeral head (12 days: $p=0.066 ; 19$ days: $p=0.821)$ or supraspinatus insertion (12 days: $\mathrm{p}=0.085 ; 19$ days: $\mathrm{p}=$ $0.105)$ between normal and control animals at either time point. There was no difference in trabecular thickness of the humeral head between normal and G-CSF-treated animals (12 days: $p=0.599$; 19 days: $p=0.924$ ), between normal and control (12 days: $\mathrm{p}=0.837$; 19 days: $\mathrm{p}=$ 0.924), or between G-CSF-treated and control animals (12 days: $\mathrm{p}=0.939 ; 19$ days: $\mathrm{p}=0.910$ ). Furthermore, there was no difference in trabecular thickness of the supraspinatus insertion between normal and G-CSF-treated animals (12 days: $\mathrm{p}=0.789 ; 19$ days: $\mathrm{p}=0.535)$, between normal and control (12 days: $\mathrm{p}=0.678 ; 19$ days: $\mathrm{p}=$ 0.303), or between G-CSF-treated and control animals (12 days: $p=0.973 ; 19$ days: $p=0.902$ ) (Table 4). 
Table 4. Bone histomorphometry results

\begin{tabular}{|c|c|c|c|c|}
\hline \multirow{2}{*}{$\begin{array}{l}\text { Treatment } \\
\text { group }\end{array}$} & \multicolumn{2}{|l|}{ Humeral head } & \multicolumn{2}{|l|}{ Supraspinatus tendon insertion } \\
\hline & $\begin{array}{l}\mathrm{BV} / \mathrm{TV}(\%) \\
(\text { mean } \pm \mathrm{SD}[95 \% \mathrm{CI}])\end{array}$ & $\begin{array}{l}\text { Tb.Th }(\mu \mathrm{m}) \\
(\text { mean } \pm \text { SD }[95 \% \mathrm{CI}])\end{array}$ & $\begin{array}{l}\mathrm{BV} / \mathrm{TV}(\%) \\
(\text { mean } \pm \mathrm{SD}[95 \% \mathrm{CI}])\end{array}$ & $\begin{array}{l}\text { Tb.Th }(\mu \mathrm{m}) \\
(\text { mean } \pm \mathrm{SD}[95 \% \mathrm{CI}])\end{array}$ \\
\hline Normal & $32.50 \pm 2.38(29.99-35.01)$ & $82.66 \pm 6.86(75.45-89.86)$ & $33.36 \pm 1.69(31.58-35.14)$ & $88.62 \pm 14.58(73.31-103.9)$ \\
\hline \multicolumn{5}{|l|}{ Control } \\
\hline 12 days & $26.87 \pm 4.41(19.85-33.90)$ & $78.64 \pm 1.49(76.26-81.02)$ & $26.89 \pm 5.36(18.39-35.46)$ & $80.47 \pm 9.13(65.94-95.01)$ \\
\hline 19 days & $29.89 \pm 10.8(16.43-43.35)$ & $86.07 \pm 12.7(70.27-101.8)$ & $24.81 \pm 8.79(13.89-35.74)$ & $76.45 \pm 8.76(65.57-87.34)$ \\
\hline \multicolumn{5}{|l|}{ G-CSF } \\
\hline 12 days & $24.89 \pm 3.80(20.17-29.60)^{*}$ & $76.17 \pm 17.1(54.89-97.45)$ & $25.67 \pm 5.33(19.04-32.29)^{*}$ & $82.69 \pm 18.1(60.23-105.1)$ \\
\hline 19 days & $28.81 \pm 6.45(20.80-36.83)$ & $82.16 \pm 22.2(54.51-109.8)$ & $27.40 \pm 7.12(18.55-36.24)$ & $80.03 \pm 14.3(62.23-97.83)$ \\
\hline
\end{tabular}

*Significant difference from normal; ${ }^{\dagger}$ significant difference between 12 and 19 days; BV/TV $=$ relative bone volume; Tb.Th. $=$ mean trabecular thickness; G-CSF = granulocyte-colony stimulating factor.

Table 5. Results from stress relaxation testing

\begin{tabular}{llll}
\hline $\begin{array}{l}\text { Treatment } \\
\text { group }\end{array}$ & $\begin{array}{l}\text { Peak stress }(\mathrm{MPa}) \\
(\text { mean } \pm \text { SD }[95 \% \mathrm{CI}])\end{array}$ & $\begin{array}{l}\text { Equilibrium stress }(\mathrm{MPa}) \\
(\text { mean } \pm \text { SD }[95 \% \mathrm{CI}])\end{array}$ & $\begin{array}{l}\text { Percent relaxation } \\
(\mathrm{mean} \pm \mathrm{SD}[95 \% \mathrm{CI}])\end{array}$ \\
\hline $\begin{array}{l}\text { Normal } \\
\text { Control }\end{array}$ & $0.98 \pm 0.49(0.57-1.39)$ & $0.70 \pm 0.36(0.40-1.01)$ & $28.17 \pm 5.66(23.44-32.90)$ \\
12 days & $0.09 \pm 0.05(0.04-0.13)^{*}$ & $0.030 \pm 0.02(0.01-0.04)^{*}$ & $66.80 \pm 5.93(61.84-71.76)^{*}$ \\
19 days & $0.17 \pm 0.08(0.10-0.23)^{*},^{\dagger}$ & $0.070 \pm 0.04(0.04-0.10)^{*},^{\dagger}$ & $58.48 \pm 7.68(52.05-64.90)^{*},^{\dagger}$ \\
G-CSF & $0.10 \pm 0.05(0.05-0.14)^{*}$ & & $65.04 \pm 7.20(58.38-71.69) *$ \\
12 days & $0.16 \pm 0.08(0.09-0.22)^{*}$ & $0.033 \pm 0.01(0.02-0.04)^{*}$ & $63.33 \pm 13.37(52.15-74.50) *$ \\
19 days & & $0.065 \pm 0.05(0.02-0.11)^{*}$ & \\
\hline
\end{tabular}

*Significant difference from normal; ${ }^{\dagger}$ significant difference between 12 and 19 days; G-CSF = granulocyte-colony stimulating factor.

\section{Biomechanical Properties}

Results from stress relaxation testing indicate that, compared with control animals, G-CSF treatment did not induce a significant difference in peak stress (MPa), equilibrium stress (MPa), or percent relaxation at either 12 days ( $\mathrm{p}=1.000, \mathrm{p}=1.000$, and $\mathrm{p}=0.931$, respectively) or 19 days $(\mathrm{p}=1.000, \mathrm{p}=1.000$, and $\mathrm{p}=0.682$, respectively) (Table 5). G-CSF-treated animals also exhibited no significant difference in peak stress (MPa), equilibrium stress (MPa), or percent relaxation $(\mathrm{p}=0.109, \mathrm{p}=0.138$, and $\mathrm{p}=$ 0.768 , respectively) between 12 and 19 days. However, there was a significant increase for control animals between 12 and 19 days in peak stress (MPa), equilibrium stress (MPa), and percent relaxation $(\mathrm{p}=0.027, \mathrm{p}=0.010$, and $p=0.030$, respectively). Normal animals exhibited significantly superior properties for all stress relaxation parameters compared with both treatment groups at 12 and 19 days ( $p<0.001$ for all comparisons).

Results from failure testing indicate no significant difference in ultimate stress (MPa), ultimate strain, modulus
$(\mathrm{MPa})$, or yield stress $(\mathrm{MPa})$ and yield strain between G-CSF-treated and control animals at either 12 days $(\mathrm{p}=$ $1.000, \mathrm{p}=0.104, \mathrm{p}=1.000, \mathrm{p}=0.909$, and $\mathrm{p}=0.483$, respectively) or 19 days $(\mathrm{p}=0.999, \mathrm{p}=0.964, \mathrm{p}=1.000$, $\mathrm{p}=0.988$, and $\mathrm{p}=0.904$, respectively) (Table 6). G-CSFtreated animals exhibited no significant difference in ultimate stress $(\mathrm{MPa})$, ultimate strain, yield stress $(\mathrm{MPa})$, or yield strain between 12 and 19 days $(\mathrm{p}=0.082, \mathrm{p}=0.463$, $\mathrm{p}=0.130$, and $\mathrm{p}=0.223$, respectively). However, there was a significant increase in modulus (MPa) $(\mathrm{p}=0.035)$. For control animals, no significant difference was found between 12 and 19 days in ultimate strain $(p=0.093)$ or yield strain $(\mathrm{p}=0.155)$, but there was a significant increase in ultimate stress $(\mathrm{MPa})(\mathrm{p}=0.034)$, modulus $(\mathrm{MPa})(\mathrm{p}=$ $0.002)$, and yield stress $(\mathrm{MPa})(\mathrm{p}=0.049)$. Normal animals had significantly greater ultimate stress $(\mathrm{MPa})$, modulus (MPa) and yield stress (MPa) compared with both treatment groups at both 12 and 19 days $(\mathrm{p}<0.05$ for all comparisons). When compared with normal animals, ultimate strain was significantly higher in G-CSF-treated animals at 19 days $(\mathrm{p}=0.016)$ and in control animals at 
both 12 days $(p=0.005)$ and 19 days $(p=0.042)$. There was no significant difference in yield strain between normal animals and G-CSF-treated animals at either 12 days $(p=0.551)$ or 19 days $(p=0.159)$. In control animals, yield strain was significantly higher at both 12 days $(p=0.027)$ and 19 days $(\mathrm{p}=0.045)$ compared with normal animals. No significant differences in cross-sectional area were found between G-CSF and control treatment groups at either 12 days $(\mathrm{p}=0.949)$ or 19 days $(\mathrm{p}=0.757)$ (Fig. 2$)$. Cross-sectional area in control animals decreased significantly between 12 and 19 days $(p=0.016)$, whereas tendons from G-CSF-treated animals did not exhibit a significant change in cross-sectional area $(p=0.357)$. Cross-sectional area was significantly greater in tendons from both G-CSF and control animals compared with normal tendons at both 12 days $(\mathrm{p}<0.001, \mathrm{p}<0.001$, respectively) and 19 days $(\mathrm{p}<0.001, \mathrm{p}<0.001$, respectively).

\section{MRI}

There was no difference in MRI score between control and G-CSF animals at either 12 days (control: $2.3 \pm 1.8$ [confidence interval $\{\mathrm{CI}\}, 0.49-4.17)$; G-CSF: $2.7 \pm 1.8$ [CI, 1.08-4.24]; $\mathrm{p}=0.623$ ) or 19 days (control: $2.3 \pm 1.5$ [CI, 0.75-3.91]; G-CSF: $2.5 \pm 1.4$ [CI, 1.05-3.94], $\mathrm{p}=$ 0.737). Normal, intact tendons had a significantly lower MRI score $(0.33 \pm 0.51$ [CI, 0.0-0.87]) compared with both control (12 days: $p=0.029 ; 19$ days: $p=0.008)$ and G-CSF (12 days: $p=0.019 ; 19$ days: $p=0.005$ ) at both time points. There was no difference in MRI between the 12- and 19-day time points within the control $(\mathrm{p}=0.937)$ or G-CSF groups (control: $\mathrm{p}=0.589$ ).

\section{Discussion}

The precise involvement of MSCs in immune and regenerative processes of orthopaedic soft tissues has yet to be fully elucidated. Although no MSC-related orthopaedic treatment is, to date, approved for clinical use in the United States, some previous laboratory studies have demonstrated the potential of MSCs to improve tendon-to-bone healing in vivo [19-21, 33]. Despite the promise of MSCs, there are significant technical and regulatory hurdles that have precluded their widespread clinical adoption. Our study used marrow-derived stem cell mobilization in an effort to increase circulating populations of MSCs, which, in turn, may "home" to the site of rotator cuff repair to improve tendon-to-bone healing. Specifically, we administered G-CSF, a potent FDA-approved mobilization agent, after acute injury and surgical repair of the rat supraspinatus 


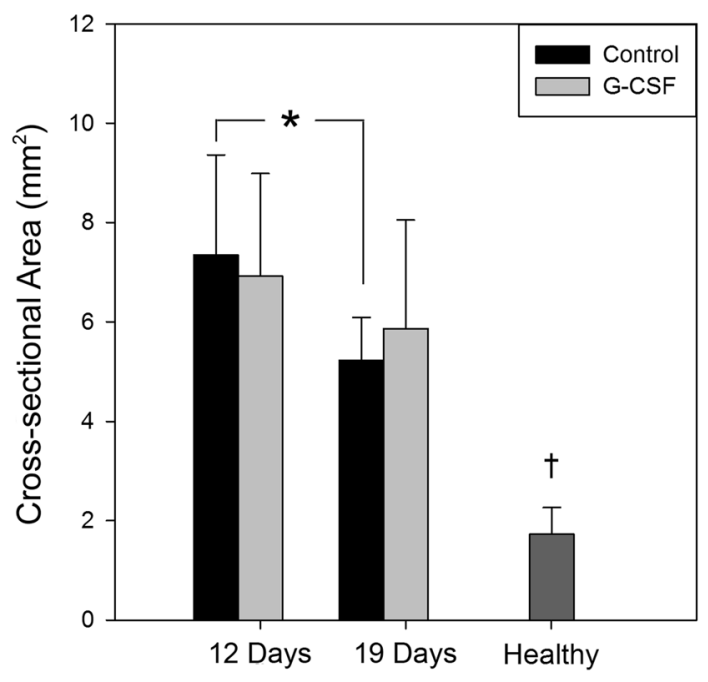

Fig. 2 Cross-sectional area of supraspinatus tendons in control, G-CSF, and healthy rat groups is shown. *Significant difference between 12 and 19 days. ${ }^{\dagger}$ Significant difference for control and GCSF rats at both 12 and 19 days.

tendon. Our results indicate that G-CSF-treated subjects displayed reduced recovery of tendon mechanical properties after cuff repair and equivocal MRI findings compared with the control group but histologic evidence of significantly increased cell recruitment to the tendon and humeral head.

This study is associated with some limitations. First, acute surgical supraspinatus injury followed immediately by surgical repair is not entirely representative of the etiology of rotator cuff disease in the human shoulder, where a tear typically develops as a consequence of gradual degeneration. Second, the rat has an inherently higher capacity to regenerate soft tissues, but we limited this effect by the use of mature rats and the use of a control group. The time points chosen in our study represented a phase of early-to-intermediate healing, and, therefore, long-term results of either group are not known. Additionally, we used micro-MRI to image the rat shoulder, but analysis of MRI data was limited by both the subjective nature of the grading system we used and the resolution limits of the system. Histologic sections analyzed in our study only provided a two-dimensional view of a relatively small volume of the tendon-to-bone insertion, but we limited this by the use of spaced sections rather than serial sections. Lastly, we did not perform an analysis of the mobilization effect of subcutaneous G-CSF administration or a phenotypic study of the cells that were recruited to the surgical site. The effect of G-CSF administration on stem cell mobilization is well established in murine and other models [11, 22, 28, 35, 37, 46].

We hypothesized that serial injections of G-CSF at $100 \mu \mathrm{g} / \mathrm{kg}$ after acute supraspinatus tendon injury and repair would increase the recruitment of marrow-derived stem cells to the site, manifested by an increase in cellularity compared with controls. G-CSF treatment increased cellularity in the operative shoulders with the most significant increases in cellularity observed within the bone tunnels and globally throughout the humeral head at each time point. Stem cell recruitment and migration are facilitated by the expression of chemokines such as CXCL12, which is the ligand for CXCR4 expressed by cells mobilized from bone marrow into circulation [37]. There is a paucity of data regarding the expression of chemokines within the rotator cuff complex, although Kim et al demonstrated that CXCL12 is overexpressed in the presence of subacromial bursitis [29]. Blaine et al also investigated the effect of local proinflammatory cytokines on CXCL12 expression within the subacromial bursa and found that interleukin- $1 \beta$ significantly increased CXCL12 expression [5]. Both studies indicated the potential for CXCL12 expression within chronically inflamed shoulder tissue, although the model we used in our study represented acute soft tissue trauma. Acute tissue injury and even surgical trauma can result in local upregulation of chemokines $[2,7]$. Future studies are planned to identify the lineage and phenotype of cells recruited to the rotator cuff complex.

Improvements in both tendon structure and enthesis metachromasia are hypothesized to be a function of increased recruitment of G-CSF-mobilized, marrow-derived MSCs. Most studies to date using stem cells to enhance rotator cuff repair have used allogeneic cells. Gulotta et al reported that transplanted allogenic MSCs did not improve the quality or strength of rotator cuff healing despite evidence of retention and metabolic activity [19]. Further studies assessed the effect of genetically modified allogeneic stem cells on rotator cuff repair, first examining the effect of allogenic MSCs treated with adenovirus-associated MT1-MMP [20] and also BMP-13 [21]. Cells overexpressing MT1-MMP demonstrated moderate increases in enthesis metachromasia, whereas ad-BMP-13 demonstrated no histologic improvement. A followup study showed that transducing allogeneic, marrow-derived MSCs with scleraxis improved the amount of fibrocartilage present at the tendon-bone interface at the 4-week time point [21]. Hernigou et al presented a case series of 45 human patients who underwent arthroscopic rotator cuff surgery augmented with a heterogenous population of stem and progenitor cells taken from intraoperative iliac crest marrow aspirates [24]. The authors reported evidence of enhanced healing through ultrasound, MRI, and functional outcomes. In our study, postoperative administration of G-CSF significantly increased cellularity in the humeral head, bone tunnels, and in the supraspinatus tendon compared with controls. Although no immunohistochemical 
staining was performed to identify the infiltrating cells, previous studies using stem cell mobilization agents in the setting of cerebrovascular ischemia [41], acute myocardial infarction [35], and lung contusion [22] demonstrated similar increases in cellularity and have determined that cells mobilized from marrow cavities indeed transmigrate into injured tissues.

Administration of G-CSF did not improve the biomechanical properties of the healing supraspinatus tendon-bone complex in our study. Although there was no difference in biomechanical properties between the control and G-CSFtreated groups, the G-CSF group exhibited less improvement between the 12- and 19-day time points compared with the control group. Studies have shown that normally healing rat supraspinatus tendons exhibit steady increases in mechanical properties $[13,17]$. Furthermore, we found that tendon cross-sectional area remained constant in the G-CSFtreated group between 12 and 19 days, whereas the control group exhibited a decrease in cross-sectional area. Dourte et al have previously shown that normally healing tendons demonstrate a steady decrease in cross-sectional area during remodeling [9]. The lack of significant increases in mechanical properties and decreases in tendon cross-sectional areas may represent delayed healing. However, increased tendon cross-sectional area could also be attributed to increased scar formation or tendon anabolism, which could assist in long-term healing and remodeling.

MRI evaluation of translational research models has been reported in the literature in larger animal models such as the sheep and canine [15, 39]. One report of a rodent model of rotator cuff injury in a mouse model further defined the use of MRI in evaluating fatty infiltration of chronic rotator cuff tear and denervation [40]. Our study, however, is the first to describe implementation of micro-MRI to evaluate the rat rotator cuff after repair. In our study, postoperative changes in the repaired tissues were evident on micro-MRI, including localized edema in the repaired tendon and inhomogeneous tendon signal. We used a qualitative grading scheme to evaluate postoperative appearance of the rat shoulder, and we found no differences in MRI scores between control and G-CSF-treated animals. Both groups had, however, significantly higher MRI scores at both time points compared with normal, intact shoulders. Micro-MRI may be implemented in future work encompassing longer postoperative time points to track tendon remodeling.

To our knowledge, this is the first study to use stem-cell mobilization agents to enhance tendon-bone healing. Our study indicates that G-CSF treatment increases local cellularity after rotator cuff repair, but this finding did not translate to improved structural healing of the supraspinatus tendon-bone complex. More research is necessary to determine which cell types were increased within the humerus and tendon and whether these are indeed bone marrow-derived stem or progenitor cells. Although G-CSF-mediated mobilization is well established, future studies are necessary to optimize mobilization schemes to maximize stem and progenitor cell concentration in blood. Finally, it is critical to elucidate whether mobilized cells are homing to the site of injury and, importantly, whether homing cells participate in regenerative or immunomodulatory mechanisms within healing tissue.

\section{References}

1. Anderlini P, Champlin RE. Biologic and molecular effects of granulocyte colony-stimulating factor in healthy individuals: recent findings and current challenges. Blood. 2008;111:1767-1772.

2. Baggiolini M. Chemokines and leukocyte traffic. Nature. 1998; 392:565-568.

3. Bedi A, Fox AJ, Kovacevic D, Deng X-H, Warren RF, Rodeo SA. Doxycycline-mediated inhibition of matrix metalloproteinases improves healing after rotator cuff repair. Am J Sports Med. 2010;38:308-317.

4. Bedi A, Kovacevic D, Hettrich C, Gulotta LV, Ehteshami JR, Warren RF, Rodeo SA. The effect of matrix metalloproteinase inhibition on tendon-to-bone healing in a rotator cuff repair model. J Shoulder Elbow Surg. 2010;19:384-391.

5. Blaine TA, Cote MA, Proto A, Mulcahey M, Lee FY, Bigliani LU. Interleukin-1 $\beta$ stimulates stromal-derived factor- $1 \alpha$ expression in human subacromial bursa. J Orthop Res. 2011;29:1695-1699.

6. Cole BJ, McCarty LP 3rd, Kang RW, Alford W, Lewis PB, Hayden JK. Arthroscopic rotator cuff repair: prospective functional outcome and repair integrity at minimum 2-year follow-up. J Shoulder Elbow Surg. 2007;16:579-585.

7. DeLong WG Jr, Born CT. Cytokines in patients with polytrauma. Clin Orthop Relat Res. 2004;422:57-65.

8. Doube M, Kłosowski MM, Arganda-Carreras I, Cordelières FP, Dougherty RP, Jackson JS, Schmid B, Hutchinson JR, Shefelbine SJ. BoneJ: free and extensible bone image analysis in ImageJ. Bone. 2010;47:1076-1079.

9. Dourte LM, Perry SM, Getz CL, Soslowsky LJ. Tendon properties remain altered in a chronic rat rotator cuff model. Clin Orthop Relat Res. 2010;468:1485-1492.

10. Duquin TR, Buyea C, Bisson LJ. Which method of rotator cuff repair leads to the highest rate of structural healing? A systematic review. Am J Sports Med. 2010;38:835-841.

11. Eyles JL, Roberts AW, Metcalf D, Wicks IP. Granulocyte colonystimulating factor and neutrophils-forgotten mediators of inflammatory disease. Nat Clin Pract Rheumatol. 2006;2:500-510.

12. Galatz LM, Ball CM, Teefey SA, Middleton WD, Yamaguchi K. The outcome and repair integrity of completely arthroscopically repaired large and massive rotator cuff tears. J Bone Joint Surg Am. 2004;86:219-224.

13. Galatz LM, Sandell LJ, Rothermich SY, Das R, Mastny A, Havlioglu N, Silva MJ, Thomopoulos S. Characteristics of the rat supraspinatus tendon during tendon-to-bone healing after acute injury. J Orthop Res. 2006;24:541-550.

14. Gartsman GM, Khan M, Hammerman SM. Arthroscopic repair of full-thickness tears of the rotator cuff. J Bone Joint Surg Am. 1998;80:832-840.

15. Gerber C, Meyer DC, Von Rechenberg B, Hoppeler H, Frigg R, Farshad M. Rotator cuff muscles lose responsiveness to anabolic steroids after tendon tear and musculotendinous retraction: an experimental study in sheep. Am J Sports Med. 2012;40: $2454-2461$. 
16. Gerber C, Schneeberger AG, Hoppeler H, Meyer DC. Correlation of atrophy and fatty infiltration on strength and integrity of rotator cuff repairs: a study in thirteen patients. J Shoulder Elbow Surg. 2007;16:691-696.

17. Gimbel JA, Van Kleunen JP, Mehta S, Perry SM, Williams GR, Soslowsky LJ. Supraspinatus tendon organizational and mechanical properties in a chronic rotator cuff tear animal model. $J$ Biomech. 2004;37:739-749.

18. Goutallier D, Postel J-M, Gleyze P, Leguilloux P, Van Driessche S. Influence of cuff muscle fatty degeneration on anatomic and functional outcomes after simple suture of full-thickness tears. $J$ Shoulder Elbow Surg. 2003;12:550-554.

19. Gulotta LV, Kovacevic D, Ehteshami JR, Dagher E, Packer JD, Rodeo SA. Application of bone marrow-derived mesenchymal stem cells in a rotator cuff repair model. Am J Sports Med. 2009;37:2126-2133.

20. Gulotta LV, Kovacevic D, Montgomery S, Ehteshami JR, Packer JD, Rodeo SA. Stem cells genetically modified with the developmental gene MT1-MMP improve regeneration of the supraspinatus tendon-to-bone insertion site. Am J Sports Med. 2010;38:1429-1437.

21. Gulotta LV, Kovacevic D, Packer JD, Deng XH, Rodeo SA. Bone marrow-derived mesenchymal stem cells transduced with scleraxis improve rotator cuff healing in a rat model. Am J Sports Med. 2011;39:1282-1289.

22. Hannoush EJ, Sifri ZC, Elhassan IO, Mohr AM, Alzate WD, Offin M, Livingston DH. Impact of enhanced mobilization of bone marrow derived cells to site of injury. J Trauma. 2011;71:283-291.

23. Hee CK, Dines JS, Dines DM, Roden CM, Wisner-Lynch LA, Turner AS, McGilvray KC, Lyons AS, Puttlitz CM, Santoni BG. Augmentation of a rotator cuff suture repair using rhPDGF-BB and a type I bovine collagen matrix in an ovine model. Am J Sports Med. 2011;39:1630-1639.

24. Hernigou P, Lachaniette CHF, Delambre J, Zilber S, Duffiet P, Chevallier N, Rouard H. Biologic augmentation of rotator cuff repair with mesenchymal stem cells during arthroscopy improves healing and prevents further tears: a case-controlled study. Int Orthop. 2014;38:1811-1818.

25. Ide J, Kikukawa K, Hirose J, Iyama K-i, Sakamoto H, Mizuta H. The effects of fibroblast growth factor- 2 on rotator cuff reconstruction with acellular dermal matrix grafts. Arthroscopy. 2009;25:608-616.

26. Isakova IA, Lanclos C, Bruhn J, Kuroda MJ, Baker KC, Krishnappa V, Phinney DG. Allo-reactivity of mesenchymal stem cells in rhesus macaques is dose and haplotype dependent and limits durable cell engraftment in vivo. PloS One. 2014;9:e87238.

27. Jost B, Pfirrmann CW, Gerber C. Clinical outcome after structural failure of rotator cuff repairs. J Bone Joint Surg Am. 2000;82:304-314.

28. Kang SK, Shin IS, Ko MS, Jo JY, Ra JC. Journey of mesenchymal stem cells for homing: strategies to enhance efficacy and safety of stem cell therapy. Stem Cells Int. 2012;2012: 342968.

29. Kim YS, Bigliani LU, Fujisawa M, Murakami K, Chang SS, Lee HJ, Lee FY, Blaine TA. Stromal cell-derived factor 1 (SDF-1, CXCL12) is increased in subacromial bursitis and downregulated by steroid and nonsteroidal anti-inflammatory agents. $J$ Orthop Res. 2006;24:1756-1764.

30. Koike Y, Trudel G, Uhthoff HK. Formation of a new enthesis after attachment of the supraspinatus tendon: a quantitative histologic study in rabbits. J Orthop Res. 2005;23:1433-1440.

31. Lee E, Bishop JY, Braman JP, Langford J, Gelber J, Flatow EL. Outcomes after arthroscopic rotator cuff repairs. J Shoulder Elbow Surg. 2007;16:1-5.
32. Maffulli N, Longo UG, Franceschi F, Rabitti C, Denaro V. Movin and Bonar scores assess the same characteristics of tendon histology. Clin Orthop Relat Res. 2008;466:1605-1611.

33. Nourissat G, Diop A, Maurel N, Salvat C, Dumont S, Pigenet A, Gosset M, Houard X, Berenbaum F. Mesenchymal stem cell therapy regenerates the native bone-tendon junction after surgical repair in a degenerative rat model. PloS One. 2010;5:e12248.

34. Opsha O, Malik A, Baltazar R, Primakov D, Beltran S, Miller TT, Beltran J. MRI of the rotator cuff and internal derangement. Eur J Radiol. 2008;68:36-56.

35. Orlic D, Kajstura J, Chimenti S, Limana F, Jakoniuk I, Quaini F, Nadal-Ginard B, Bodine DM, Leri A, Anversa P. Mobilized bone marrow cells repair the infarcted heart, improving function and survival. Proc Natl Acad Sci U S A. 2001;98:10344-10349.

36. Peltz CD, Sarver JJ, Dourte LM, Würgler-Hauri CC, Williams GR, Soslowsky LJ. Exercise following a short immobilization period is detrimental to tendon properties and joint mechanics in a rat rotator cuff injury model. J Orthop Res. 2010;28:841-845.

37. Petit I, Szyper-Kravitz M, Nagler A, Lahav M, Peled A, Habler L, Ponomaryov T, Taichman RS, Arenzana-Seisdedos F, Fujii N. GCSF induces stem cell mobilization by decreasing bone marrow SDF-1 and up-regulating CXCR4. Nat Immunol. 2002;3:687-694.

38. Reeder JD, Andelman S. The rotator cuff tear: MR evaluation. Magn Reson Imaging. 1987;5:331-338.

39. Safran O, Derwin KA, Powell K, Iannotti JP. Changes in rotator cuff muscle volume, fat content, and passive mechanics after chronic detachment in a canine model. J Bone Joint Surg Am. 2005;87:2662-2670.

40. Samagh SP, Kramer EJ, Melkus G, Laron D, Bodendorfer BM, Natsuhara K, Kim HT, Liu X, Feeley BT. MRI quantification of fatty infiltration and muscle atrophy in a mouse model of rotator cuff tears. J Orthop Res. 2013;31:421-426.

41. Shyu W-C, Lin S-Z, Lee C-C, Liu DD, Li H. Granulocyte colony-stimulating factor for acute ischemic stroke: a randomized controlled trial. CMAJ. 2006;174:927-933.

42. Slabaugh MA, Nho SJ, Grumet RC, Wilson JB, Seroyer ST, Frank RM, Romeo AA, Provencher MT, Verma NN. Does the literature confirm superior clinical results in radiographically healed rotator cuffs after rotator cuff repair? Arthroscopy. 2010;26:393-403.

43. Steinert AF, Rackwitz L, Gilbert F, Nöth U, Tuan RS. Concise review: the clinical application of mesenchymal stem cells for musculoskeletal regeneration: current status and perspectives. Stem Cells Transl Med. 2012;1:237-247.

44. Thomopoulos S, Williams G, Soslowsky L. Tendon to bone healing: differences in biomechanical, structural, and compositional properties due to a range of activity levels. J Biomech Eng. 2003; 125:106-113.

45. Trillet-Lenoir V, Green J, Manegold C, Von Pawel J, Gatzemeier U, Lebeau B, Depierre A, Johnson P, Decoster G, Tomita D. Recombinant granulocyte colony stimulating factor reduces the infectious complications of cytotoxic chemotherapy. Eur J Cancer. 1993;29:319-324.

46. Welte K, Gabrilove J, Bronchud MH, Platzer E, Morstyn G. Filgrastim (r-metHuG-CSF): the first 10 years. Blood. 1996;88: 1907-1929.

47. Wilson F, Hinov V, Adams G. Arthroscopic repair of fullthickness tears of the rotator cuff: 2- to 14-year follow-up. Arthroscopy. 2002;18:136-144.

48. Wood AJ, Lieschke GJ, Burgess AW. Granulocyte colony-stimulating factor and granulocyte-macrophage colonystimulating factor. $N$ Engl J Med. 1992;327:28-35.

49. Zhao W, Phinney DG, Bonnet D, Dominici M, Krampera M. Mesenchymal stem cell biodistribution, migration, and homing in vivo. Stem Cells Int. 2014;2014:292109. 